\title{
Qualidade de água para consumo humano em Riacho Frio, Piauí
}

O Brasil é um país privilegiado pelo manancial que dispõe. As águas subterrâneas são fundamentais para o abastecimento público no Brasil, muitas regiões dependem dos mananciais subterrâneos, no entanto, a distribuição natural desse recurso não é equilibrada. O estado do Piauí está inserido nesta realidade: as fontes subterrâneas de abastecimentos os recursos naturais utilizados tradicionalmente para abastecer essas regiões. As águas subsuperficiais também estão susceptíveis a contaminação. O presente trabalho buscou avaliar a qualidade da água subsuperficial utilizada no sistema de abastecimento humano da cidade de Riacho Frio, Estado do Piauí. O sistema de captação e distribuição de água do município é composto por dois poços tubulares e uma estação elevatória de onde prossegue a distribuição da água pelo sistema de abastecimento da cidade. Foram realizadas campanhas de coleta de amostras em períodos secos e chuvosos. Para cada amostra coletada foram analisados parâmetros físico-químicos, bioquímicos e microbiológicos da água e prosseguiu-se com o enquadramento ao padrão definido pelas resoluções do CONAMA 357/2005 e 396/2008 e portaria do MS 05/2017, bem como construção do Índice de Qualidade de Água (IQA). Em todos os pontos, em ambos os períodos de coleta, o IQA foi enquadrado como nível 'bom' ou 'ótimo', sendo a qualidade da água considerada satisfatória. Nos dados do período seco, todas as amostras de $\mathrm{OD}, 75 \%$ das amostras de coliformes termotolerantes, não estão adequadas conforme o padrão, já no período chuvoso, em $75 \%$ das amostras de nitrogênio total e $100 \%$ das amostras de fósforo total estão em desconformidade com o padrão determinado em legislação.

Palavras-chave: Padrão de potabilidade; Índice de Qualidade de Água (IQA); Qualidade de água subsuperficial.

\section{Quality of water for human consumption in Riacho Frio, Piauí}

Brazil is a privileged country due to the wealth it has. Groundwater is essential for public supply in Brazil, many regions depend on groundwater sources, however the natural distribution of this resource is not balanced. The state of Piaui is inserted in this reality: the underground sources of supply the natural resources traditionally used to supply these regions. Subsurface waters are also susceptible to contamination. The present work sought to evaluate the quality of subsurface water used in the human supply system in the city of Riacho Frio, State of Piauí. The municipality's water collection and distribution system consists of two tubular wells and a lifting station from which water distribution continues through the city's water supply system. Sampling campaigns were carried out in dry and rainy periods. For each sample collected, physical-chemical, biochemical and microbiological parameters of the water were analyzed and the framework continued with the standard defined by the resolutions of the CONAMA 357/2005 y 396/2008 and ordinance of MS 05/2017, as well as construction of the Water Quality Index (IQA). At all points, in both collection periods, the IQA was classified as a 'good' or 'excellent' level, with water quality considered satisfactory. In the dry period data, all OD samples, $75 \%$ of the thermotolerant coliform samples, are not adequate according to the standard, while in the rainy season, $75 \%$ of the total nitrogen samples and $100 \%$ of the total phosphorus samples are in non-compliance with the standard determined by legislation.

Keywords: Potability standard; Water Quality Index (AQI); Subsurface water quality.

Topic: Uso de Recursos Naturais

Reviewed anonymously in the process of blind peer.
Received: 09/08/2020

Approved: 25/09/2020
Rômulo Vargas Lustosa (iD

Instituto Federal Goiano, Brasil

http://lattes.cnpq.br/1902042137489859

http://orcid.org/0000-0002-2683-7576

vargas-romulo@hotmail.com

Bruna de Freitas Iwata (D)

Instituto Federal do Piauí, Brasil

http://lattes.cnpq.br/3036032785449787

http://orcid.org/0000-0002-6465-9731

iwata@ufpi.edu.br

Anaian Antunes Bembem (iD

Instituto Federal do Piauí, Brasil

http://lattes.cnpq.br/9652102577830650

http://orcid.org/0000-0003-3557-6336

anaian@ifpi.edu.br

\author{
Temístocles Pacheco Lima (iD) \\ Instituto Federal Goiano, Brasil \\ http://lattes.cnpq.br/2260923828745202 \\ http://orcid.org/0000-0002-0632-0473 \\ temistoclespacheco@hotmail.com \\ Ítalo Rômulo Mendes de Souza \\ Instituto Federal Goiano, Brasil \\ http://lattes.cnpq.br/5588612317584029 \\ http://orcid.org/0000-0002-3975-0402 \\ italo romulo@hotmail.com \\ Leandro Caixeta Salomão (iD \\ Instituto Federal Goiano, Brasil \\ http://lattes.cnpq.br/0048021809961606 \\ http://orcid.org/0000-0001-9436-1488 \\ leandro.salomao@ifgoiano.edu.br
}

\section{Referencing this:}

LUSTOSA, R. V.; IWATA, B. F.; BEMBEM, A. A.; LIMA, T. P.; SOUZA, I. R. M.; SALOMÃO, L. C.. Qualidade de água para consumo humano em Riacho Frio, Piauí. Revista Ibero Americana de Ciências Ambientais, v.11, n.5, p.600-611, 2020. DOI: http://doi.org/10.6008/CBPC2179$\underline{6858.2020 .005 .0054}$ 


\section{INTRODUÇÃO}

A garantia da disponibilidade hídrica para as próximas gerações é uma preocupação que alcança toda a sociedade. Especialmente nos fundamentos da Política Nacional de Recursos Hídricos (PNRH), onde a água é defendida como sendo um bem de domínio público, bem como, um recurso natural limitado, dotado de valor econômico (BRASIL, 1997) e, desse modo, considerando ainda essas especificidades, o cuidado e a utilização racional devem ser prioridades.

O Brasil é um país privilegiado pelo manancial (superficial e subsuperficial) que dispõe. Não obstante, as políticas públicas de preservação e conservação deste bem devem acompanhar as proporções do seu potencial hidrológico. Outro ponto, não menos importante que a proteção dos mananciais, é a garantia de consumo humano de água segundo padrões de potabilidade adequados e relevantes para a saúde pública (BRASIL, 2006; VOTTRI, 2018).

No Brasil, onde muitas regiões dependem dos mananciais subterrâneos, mais da metade dos municípios brasileiros (53\%) dependem de fontes hídricas subsuperficiais para o abastecimento (ARID, 2019). Desse modo, indispensável à sobrevivência humana, existência de vida e manutenção do equilíbrio global, a água deve sempre transpor as discussões, especialmente ambientais. As águas subterrâneas são fundamentais para o abastecimento público no Brasil (ANA, 2010). Programas e instituições nacionais e internacionais propõem identificar os principais problemas de poluição dessas águas e preparar subsídios tecnológicos para avaliação e prevenção, a fim de garantir a saúde pública (ARID, 2019).

Por mais que o Brasil possua importante potencial hídrico, em comparação com outras regiões do planeta, a distribuição natural desse recurso não é equilibrada (ANA, 2007). O Nordeste, por exemplo, é a região do país que apresenta maior déficit hídrico, sendo caracterizada por reduzidas precipitações, elevada evaporação e pouca disponibilidade de águas superficiais, dessa forma, as reservas hídricas subterrâneas constituem uma alternativa para o abastecimento humano (NANES, 2012).

A exploração desordenada e as frequentes intervenções humanas sobre a Natureza, incluindo o avanço das diferentes formas de poluição e de degradação do meio ambiente, vêm impactando seriamente os recursos existentes, tornando sua utilização cada dia mais difícil e onerosa (BOMTEMPO, 1999; JACOBI, 2003; CUNHA et al., 2014).

O estado do Piauí está inserido nesta realidade. Sofre há anos com falta ou insuficiência de água até mesmo para o consumo humano, em algumas regiões, sendo as fontes subterrâneas de abastecimentos os recursos naturais utilizados tradicionalmente para abastecer essas regiões. Entretanto, o crescimento deste modo de abastecimento foi acompanhado da proliferação de poços construídos, sem levar em conta critérios técnicos adequados que permitissem condições qualitativas básicas de potabilidade (CAPP et al., 2012).

A magnitude e a toxicidade das águas efluentes, contudo, muitas vezes supera a capacidade depurativa dos ecossistemas, acabando por degradar a qualidade da água, local e regionalmente (ANA, 2011a). Portanto, a qualidade da água está se deteriorando em muitos pontos do curso d'água. É o que acontece com as águas subsuperficiais que, embora, teoricamente, estejam mais protegidas de 
contaminação, pela dificuldade de acesso, a perfuração de poços com locação inadequada coloca em risco a qualidade destas, uma vez que gera uma conexão entre as águas mais rasas, e, portanto, mais suscetíveis à contaminação, com águas mais profundas menos vulneráveis (ANA, 2007; 2011a).

Atualmente, além dos requisitos bacteriológicos, devem ser determinados também os contaminantes físico-químicos para definir a potabilidade da água, inclusive de água subsuperficial, quando esta é destinada para o consumo humano (ARID, 2019). Nesse contexto surge a importância de se estimar o Índice de Qualidade da Água (IQA) destinada para consumo humano, uma vez que este índice foi desenvolvido para avaliar a qualidade da água bruta visando seu uso para o abastecimento público, após tratamento. Os parâmetros utilizados no cálculo do IQA são indicadores de contaminação (BRASIL, 1997; ANA, 2011b).

As soluções para o problema de degradação da qualidade de águas de superfícies têm sido encontradas na implementação de uma legislação efetiva para interromper as emissões de contaminantes (CELLIGOI, 1999; ARAÚJO, 2009). Infelizmente, os problemas de degradação da qualidade das águas subterrâneas são mais difíceis de serem superados. Uma vez que heterogeneidades são inerentes aos sistemas de subsuperfície, as zonas de águas subterrâneas degradadas são muito difíceis de se detectar (STROHSCHOEN et al., 2006).

O município de Riacho Frio, estado do Piauí é exemplo desta realidade exposta anteriormente: quase a totalidade da população consome água subsuperficial, boa parte oriunda de poços artesianos. Considerando toda essa situação exposta, o presente trabalho buscou avaliar a qualidade da água subsuperficial utilizada no sistema de abastecimento humano da cidade de Riacho Frio, Estado do Piauí.

\section{MATERIAIS E MÉTODOS}

\section{Área de estudo}

O município de Riacho Frio, Estado do Piauí, possui uma área total aproximada de 2.221 quilômetros quadrados. O município está situado na Microrregião das Chapadas do Extremo Sul Piauiense, fazendo fronteira com 7 (sete) municípios piauienses, a saber: Parnaguá, Curimatá, Redenção do Gurgueia, Monte Alegre do Piauí, Gilbués, São Gonçalo do Gurgueia e Corrente, conforme mostra a figura 1. Dista, em média, $800 \mathrm{~km}$ da capital do estado, Teresina. Dados do último levantamento censitário apontam uma população de 4.241 habitantes (IBGE, 2010).

No município, não há rio perene, apenas riachos, sendo os principais: o "Riacho Frio" e o "Rio Fundo", ambos afluentes direto da lagoa de Parnaguá, possuindo, predominantemente, uma vegetação característica do bioma Cerrado (INFOSANBAS, 2017; MMA, 2019). O clima da região em estudo, conforme o IBGE (2002) e Fundação CEPRO (2011), é tropical semiúmido, possuindo verão chuvoso e inverno seco. Apresenta as temperaturas mínimas médias de $20^{\circ} \mathrm{C}$ e máximas de $36^{\circ} \mathrm{C}$ e, precipitação pluviométrica anual média de 900 mm (INMET, 2018). 


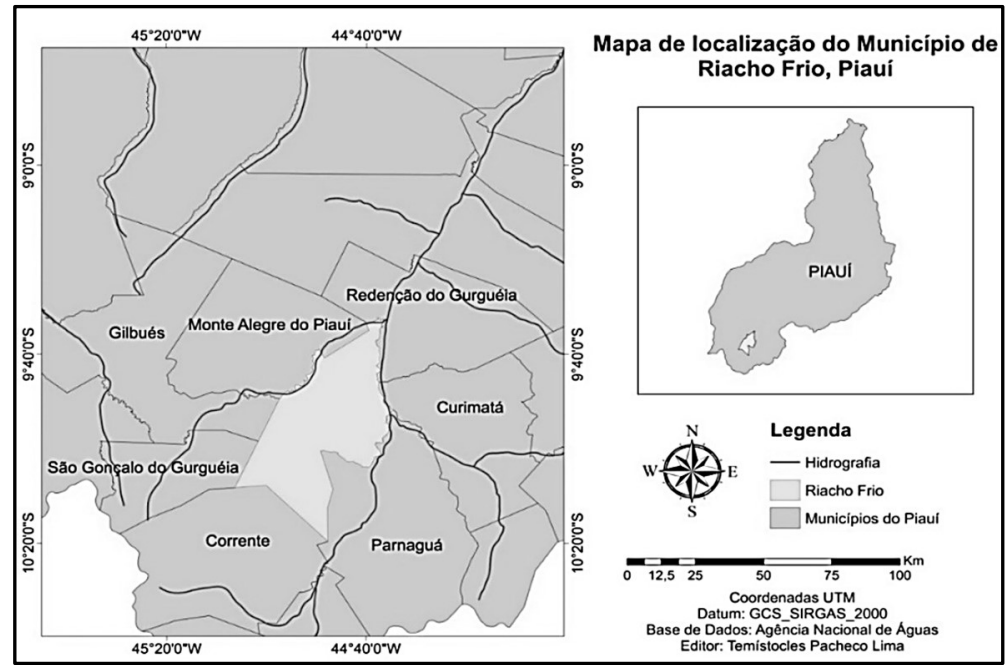

Figura 1: Mapa de localização do município de Riacho Frio, Piauí. Fonte: Lustosa et al. (2016).

O município integra a Sub-bacia Hidrográfica Uruçuí/Preto/Gurguéia, que compõem a Região Hidrográfica do Parnaíba. Todo o sistema de abastecimento de água do município é feito pela empresa Águas e Esgotos do Piauí Ltda. (AGESPISA). O sistema de captação e distribuição de água do município é composto por dois poços tubulares e uma estação elevatória de onde prossegue a distribuição da água pelo sistema de abastecimento da cidade (ANA, 2012). Ainda apresentando dados da Agência Nacional de Águas (ANA) para o município, a situação do abastecimento, segundo o último levantamento (2015) era considerada satisfatória e que a avaliação oferta/demanda de água até 2015 também era considerada satisfatória.

\section{Delineamento experimental}

\section{Identificação dos pontos de coleta das amostras}

Foram realizadas visitas in loco nos dois pontos de captação da água (poços artesianos) para definição de pontos de coletas, bem como, demais pontos para construção do delineamento experimental da área de estudo, totalizando 04 (quatro) pontos de coleta de amostras (Tabela 1). A identificação dos pontos amostrais se deu da seguinte forma: dois poços tubulares (pontos 'P01' e 'P02', respectivamente) onde é feita a captação da água e posterior bombeamento para a estação elevatória; no ponto descrito como 'P03' foi coletada amostra após a estação elevatória - após tratamento, teoricamente; o 'P04' é amostra da água ao chegar à residência pelo sistema de abastecimento. A obtenção dos dados espaciais em campo (coordenadas) ocorreu com o uso de receptor GPS.

Tabela 1: Identificação dos pontos de coleta de amostras de água.

\begin{tabular}{lll}
\hline Ponto & Identificação & Coordenadas geográficas \\
\hline P01 & Poço tubular da praça & $10907^{\prime} 34.3^{\prime \prime}$ S / 44057'06.1" O \\
P02 & Poço tubular da caixa & $10907^{\prime} 45.8^{\prime \prime}$ S / 44957'08.7" O \\
P03 & Logo após a estação elevatória & $10907^{\prime} 45.6^{\prime \prime}$ S / 44957'08.9" O \\
P04 & Residência & $10907^{\prime} 33.6^{\prime \prime}$ S / 44ㅇ5'04.7" O \\
\hline
\end{tabular}

\section{Avaliação da qualidade da água para consumo humano}

As coletas de amostras de água dos pontos ocorreram nos períodos seco e chuvoso. A variabilidade sazonal foi observada de acordo com informações pluviométricas disponibilizadas pelo Instituto Nacional de 
Meteorologia (INMET), com dados do ano de 2019, sendo que na campanha de coleta do período seco, mês de junho de 2019, foi registrado $0 \mathrm{~mm}$ de precipitação e, no período chuvoso, dezembro de 2019, pouco menos de 50 mm (INMET, 2019).

Os parâmetros (físico-químicos, bioquímicos e microbiológicos da água) analisados foram os constituintes do IQA. O IQA é o principal indicador qualitativo usado no país (ANA, 2011b). Ele é calculado com base nos seguintes parâmetros: temperatura da água, pH, oxigênio dissolvido (OD), resíduo total, demanda bioquímica de oxigênio (DBO), coliformes termotolerantes, nitrogênio total, fósforo total e turbidez; e os valores foram aferidos pelos equipamentos apresentados na tabela 2, a seguir, que apresentam metodologias próprias.

Tabela 2: Unidades de medida e equipamentos adotados para análise dos parâmetros físico-químico, bioquímico e microbiológico.

\begin{tabular}{lll}
\hline Parâmetro & Unidade de medida & Equipamento \\
\hline Oxigênio dissolvido & $\mathrm{mg} / \mathrm{L}$ & Oxímetro (Lutron) - DO-5519 \\
Temperatura & ${ }^{\circ} \mathrm{C}$ & Termômetro digital - TE07 \\
C. termotolerantes & $\mathrm{NPM} / 100 \mathrm{~mL}$ & Meio cromogênio em DIP em papel - Colipaper \\
$\mathrm{pH}$ & - & pHmetro (Lutron) - PH 221 \\
$\mathrm{DBO}$ & $\mathrm{mg} / \mathrm{L}$ & Método volumétrico (Alfakit) \\
Nitrogênio total & $\mathrm{mg} / \mathrm{L}$ & Fotocolorímetro (Alfakit) \\
Fosforo total & $\mathrm{mg} / \mathrm{L}$ & Fotocolorímetro (Alfakit) \\
Turbidez & $\mathrm{UNT}$ & Turbidímetro microprocessado (Alfakit) \\
Resíduo total & $\mathrm{mg} / \mathrm{L}$ & Método gravimétrico \\
\hline
\end{tabular}

Fonte: Rocha (2010), adaptado.

Os valores máximos permitidos, bem como os mínimos exigidos foram levantados na legislação brasileira. Pode-se citar: Portaria de Consolidação do Ministério da Saúde (MS) no 05/2017, para enquadrar os parâmetros pH, Fósforo Total e Turbidez; Resolução do CONAMA 396/2008 (águas subterrâneas), para enquadramento de Coliformes Termotolerantes, Sólidos Totais e Nitrogênio Total; e CONAMA 357/2005 (águas superficiais, mas também apresenta limites para consumo humano), para proceder com o enquadramento de Oxigênio Dissolvido (OD) e Demanda Bioquímica de Oxigênio (DBO).

As amostras foram coletadas, preservadas e transportadas conforme as recomendações do Guia Nacional de Coleta e Preservação de Amostras de Água (CETESB, 1987; ANA, 2011b) e encaminhadas para o laboratório de Água e Solos do Instituto Federal do Piauí - Campus Corrente e analisadas conforme método de referência "Standard Methods" (Tabela 2) da Associação Americana de Saúde Pública (APHA, 2012; ROCHA, 2019).

\section{Índice de Qualidade da Água}

A partir de um estudo realizado em 1970 pela "National Sanitation Foundation" (NSF) dos Estados Unidos, a Companhia Ambiental do Estado de São Paulo (CETESB) adaptou e desenvolveu o Índice de Qualidade das Águas (IQA) que incorpora nove variáveis consideradas relevantes para a avaliação da qualidade das águas, tendo como determinante principal a sua utilização para abastecimento público (ANA, 2018; CETESB, 2018).

O IQA, em geral, é um número adimensional que exprime a qualidade da água para os diversos fins. 
Esse número é obtido da agregação de dados físico-químicos, bacteriológicos, químicos por meio de metodologias específicas. Ele é calculado pelo produto ponderado das notas atribuídas cada parâmetro de qualidade de água: (1) temperatura da amostra, (2) pH, (3) oxigênio dissolvido, (4) demanda bioquímica de oxigênio (DBO) (5 dias, 20ำ), (5) coliformes fecais, (6) nitrogênio total, (7) fósforo total, (8) resíduo total e (9) turbidez. A seguinte equação é utilizada (CETESB, 1997; ANA, 2014) (Equação 1):

$$
I Q A=\prod_{i=1}^{n} q^{i^{w i}}
$$

Equação 1

Onde: IQA-NSF - Índice de Qualidade das Águas, um número entre 0 e 100; qi - qualidade do i-ésimo parâmetro, um número entre 0 e 100, obtido da respectiva "curva média de variação de qualidade", em função de sua concentração ou medida; e wi - peso correspondente ao i-ésimo parâmetro, um número entre 0 e 1 , atribuído em função da sua

$$
\sum_{i=1}^{n} w_{i}=1
$$
importância para a conformação global de qualidade, sendo que (Equação 2):

Equação 2

Em que n é 9 (número de parâmetros).

A criação do IQA baseou-se numa pesquisa de opinião junto a especialistas em qualidade de águas, que indicaram as variáveis a serem avaliadas, o peso relativo e a condição com que se apresenta cada parâmetro, segundo uma escala de valores 'rating'. Para estes foram estabelecidas curvas de variação da qualidade das águas de acordo com o estado de cada parâmetro. Estas curvas de variação, sintetizadas em um conjunto de curvas médias para cada parâmetro, bem como seu peso relativo correspondente, são apresentados na figura 3.
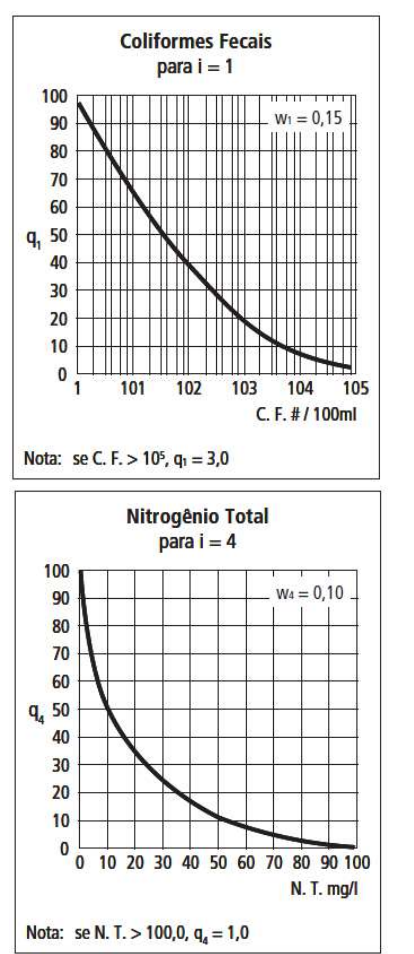
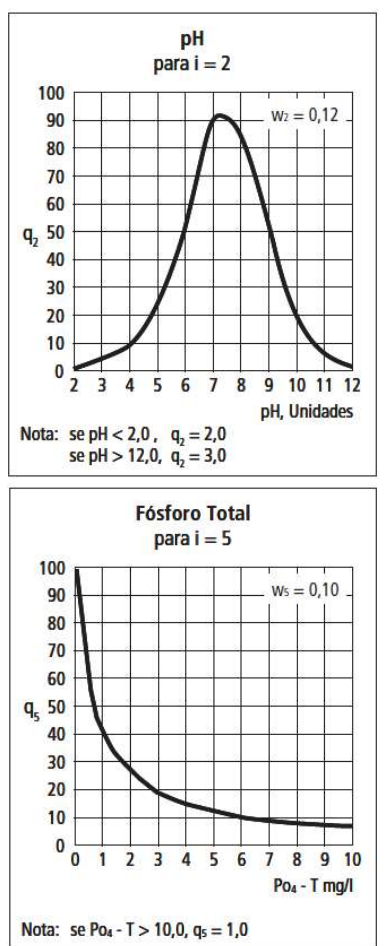
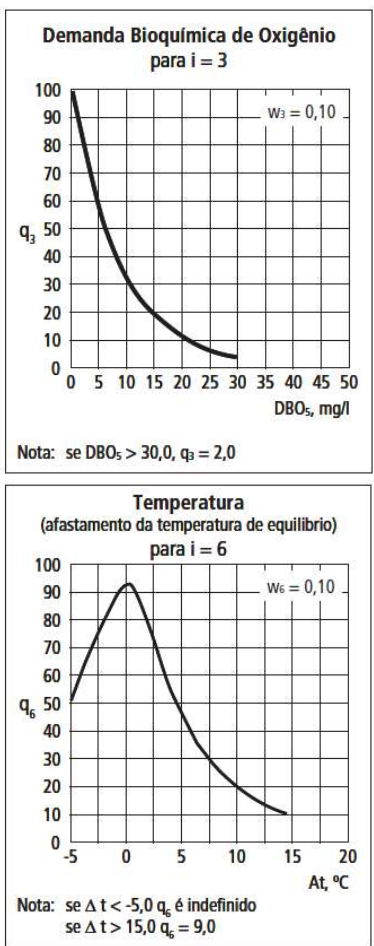

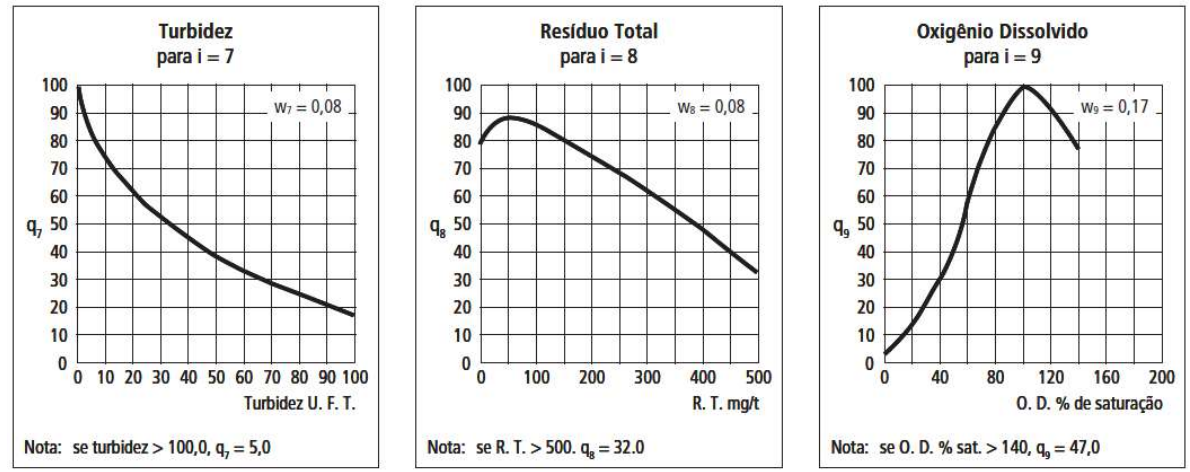

Figura 3: Curvas médias de variação de qualidade das águas. Fonte: ANA (2004); CETESB (2018).

A partir do cálculo efetuado, pode-se determinar a qualidade das águas brutas, que é indicada pelo IQA, variando numa escala de 0 a 100, representado na tabela 3.

Tabela 3: Classificação do Índice de Qualidade de Água (IQA).

\begin{tabular}{ll}
\hline Categoria & Ponderação \\
\hline ÓTIMA & $79<$ IQA $\leq 100$ \\
BOA & $51<$ IQA $\leq 79$ \\
REGULAR & $36<$ IQA $\leq 51$ \\
RUIM & $19<$ IQA $\leq 36$ \\
\hline PÉSSIMA & IQA $\leq 19$ \\
\hline
\end{tabular}

Fonte: CETESB (2018).

\section{RESULTADOS E DISCUSSÃO}

O estudo evidenciou que as referidas amostras coletadas enquadraram como classe 1 em qualidade de 'águas doces'. De acordo com a Resolução CONAMA 396 (2008), esse enquadramento é um requisito normativo onde os parâmetros de qualidade de água é o valor limite estabelecido com base nos valores de referência de qualidade e nos valores máximos permitidos (ou mínimos exigidos) para cada um dos usos preponderantes, que, neste caso, é a destinação para consumo humano.

Esse enquadramento possibilitou apontar que, no período seco, seus padrões seguiram um comportamento semelhante na maioria das amostras, com baixa variação do preconizado pelas legislações referenciais, como, por exemplo, o OD e coliformes termotolerantes e, no período chuvoso, as amostras que estão em desconformidade com o valor limite nitrogênio total, exceto no ponto 'P02', e fósforo total, em todos os pontos amostrais coletados, conforme pode ser observado na tabela 4, a seguir.

Tabela 4. Parâmetros físico-químico, bioquímico e microbiológico aferidos nas amostras dos períodos seco e chuvoso.

\begin{tabular}{|c|c|c|c|c|c|c|c|c|c|}
\hline \multirow{3}{*}{ PARÂMETROS } & \multirow{3}{*}{ VMP* } & \multicolumn{8}{|c|}{ PONTOS DE COLETA } \\
\hline & & \multicolumn{2}{|l|}{ P01 } & \multicolumn{2}{|l|}{ P02 } & \multicolumn{2}{|l|}{ P03 } & \multicolumn{2}{|l|}{ P04 } \\
\hline & & PS** & $\mathrm{PC} * * *$ & PS & $\mathrm{PC}$ & PS & $\mathrm{PC}$ & PS & $\mathrm{PC}$ \\
\hline Oxigênio Dissolvido & $\geq 5$ & 4,10 & 7,30 & 4,20 & 7,40 & 4,80 & 7,20 & 4,89 & 7,20 \\
\hline Temperatura & - & 28,00 & 29,80 & 29,00 & 31,20 & 30,00 & 30,80 & 29,00 & 32,10 \\
\hline C. termotolerantes & 0 & 78,00 & 0,00 & 0,00 & 0,00 & 78,00 & 0,00 & 80,00 & 0,00 \\
\hline $\mathrm{pH}$ & $<6$ ou $>9,5$ & 6,13 & 6,87 & 7,11 & 6,59 & 6,92 & 7,47 & 6,83 & 7,17 \\
\hline DBO & 5 & 0,20 & 2,50 & 0,10 & 2,90 & 0,15 & 3,60 & 0,20 & 3,30 \\
\hline Nitrogênio total & 2,18 & 0,08 & 4,94 & 0,08 & 0,90 & 0,08 & 2,82 & 0,07 & 4,44 \\
\hline Fósforo total & $\leq 0,1$ & 0,02 & 2,72 & 0,01 & 3,66 & 0,01 & 1,16 & 0,01 & 1,03 \\
\hline Turbidez & 5 & 1,20 & 0,00 & 1,10 & 0,00 & 1,25 & 0,00 & 1,20 & 0,00 \\
\hline Resíduo total & 940 & 2,75 & 172,19 & 3,08 & 100,50 & 3,15 & 185,59 & 3,18 & 167,50 \\
\hline
\end{tabular}

*Valor Máximo Permitido, conforme resoluções do CONAMA n 396/08 (consumo humano) e CONAMA no 357/05 
(consumo humano) e portaria de consolidação do Ministério da Saúde (MS) no 05/2017; **Período Seco; ***Período Chuvoso.

Para os valores encontrados de OD, todos os pontos no período seco apresentaram valores abaixo do mínimo permitido. Esse resultado já foi relatado na BDTD UFMG (2017) uma vez que, nas águas subterrâneas, o OD pode estar em pequena quantidade, especialmente no período seco, já que maior parte do ar dissolvido é consumido durante a percolação da água na zona de aeração.

O oxigênio dissolvido em águas naturais e degradadas depende das atividades químicas, físicas e bioquímicas do sistema. A análise de OD é um teste-chave em poluição de águas e o controle do processo de tratamento de lixo. Diminuindo-se a temperatura da água, aumenta-se a solubilidade de $\mathrm{O}_{2}$, já em temperaturas elevadas, as reações químicas ocorrem mais rapidamente, havendo um consumo maior de oxigênio pela matéria orgânica como consequência (CELLIGOI, 1999; LINS, 2010; NASCENTES et al., 2011; SILVA et al., 2017).

Para os dados de coliformes termotolerantes, apenas o 'P02' está em conformidade com o que determina a Resolução CONAMA 396/2008, ausência em 100 mL, já em todos os demais foram registrados dados de coliformes termotolerantes. Vale ressaltar que o ponto 'P02' é identificado como um poço artesiano de uso suplementar, uma vez que dele só é captada água quando há algum problema para captação do poço artesiano identificado como "P01". Desse modo, a priorização pela captação de água neste último fez com que as amostras coletadas nas etapas seguintes do abastecimento também apresentassem coliformes termotolerantes.

No universo amostral descrito, em ambos os períodos, seco e chuvoso, a temperatura da água in loco variou entre 28 e 32,1 ㅇ․ A temperatura é um dos parâmetros mais importantes da qualidade da água (OLIVEIRA et al., 2014). Influencia as taxas e os processos biogeoquímicos, além de controlar o consumo de nutrientes (WARD et al., 2013). Uma faixa de temperatura considerada ótima está entre 25 e 35 드, uma vez que, acima disso, a concentração de saturação de OD diminui, favorecendo a atividade biológica (PESSOA et al., 2009; LINS, 2010; SILVA et al., 2003).

Em todas as amostras avaliadas, período seco e chuvoso, foi registrada a concentração de DBO abaixo do limite máximo estabelecido pela resolução CONAMA no 357/2005, isto é, em conformidade com o determinado pela resolução, que define que valores de DBO não poderá exceder $5 \mathrm{mg} / \mathrm{L}$ (BRASIL, 2005). $O$ valor máximo encontrado nas amostras foi de $3,60 \mathrm{mg} / \mathrm{L}$. Os valores de DBO tem relação direta com os valores de OD (AMORIM et al., 2016; CETESB, 2018; ANA, 2018). Os maiores aumentos em termos de DBO, num corpo d'água, são provocados por despejos de origem predominantemente orgânica (LINS, 2010; NASCENTES et al., 2011). A DBO indica o potencial de consumo de OD pela matéria orgânica presente na água, se houver (VON SPERLING, 2014).

Apontado por Oliveira et al. (2014), o pH pode influir em diversos equilíbrios químicos que ocorrem naturalmente ou em processos unitários de tratamento de águas, vindo a se tornar um parâmetro importante em muitos estudos no campo do saneamento ambiental e que, segundo a CETESB (2018), o valor do pH ideal para a proteção à vida se fixa entre 6 e 9, ratificado pela Portaria de Consolidação do Ministério 
da Saúde (2017) na qual recomenda-se que, no sistema de distribuição, o pH da água seja mantido na faixa de 6,0 a 9,5. No presente estudo, os valores encontrados para pH oscilaram entre o valor mínimo de 6,13 e máximo de 7,47, desse modo, dentro do intervalo permitido.

Os parâmetros turbidez e resíduo total, nos dois períodos amostrados, estão conformidade com a legislação. O valor mínimo e máximo de turbidez são 1,10 e 1,25 UNT, respectivamente, sendo que o valor máximo permitido pela Portaria de consolidação do Ministério da Saúde no 05/2017 é de 5 UNT. Já os valores de turbidez são disciplinados pela Portaria CONAMA 396/2008, sendo o que valor máximo permitido é de $940 \mathrm{mg} / \mathrm{L}$ e o valor amostral máximo aferido foi de $185,59 \mathrm{mg} / \mathrm{L}$.

No período seco, o parâmetro fósforo total se manteve dentro dos padrões estabelecidos pela legislação vigente no que se refere a consumo humano, que preconiza o valor máximo permitido de $0,1 \mathrm{mg} / \mathrm{L}$, sendo o maior valor encontrado nas amostras de $0,02 \mathrm{mg} / \mathrm{L}$. O mesmo se aplica aos valores de nitrogênio total, para os valores aferidos no período seco. Sendo que o valor máximo permitido é de 2,18 mg/L e as amostras aferidas pelas coletas variam entre $0,01 \mathrm{mg} / \mathrm{L} \mathrm{e} 0,02 \mathrm{mg} / \mathrm{L}$. Esses dois parâmetros se encontram em ligeira alteração no período chuvoso, resultado do período de recarga do lençol subterrâneo, nitrogênio total, exceto no ponto "P02", e fósforo total, em todos os pontos amostrais coletados (Figura 4).

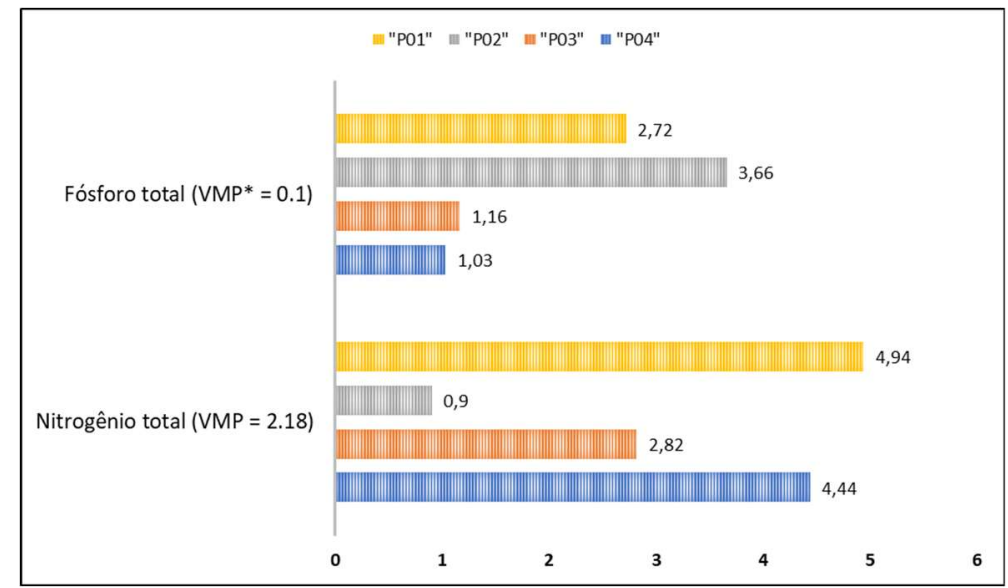

Figura 4: Valores de nitrogênio total e fósforo total do período chuvoso.

*Valor máximo permitido.

As fontes de nitrogênio são decomposição de proteínas e fonte antropogênica, como fezes de animais e fertilizantes (VON SPERLING, 2005). Em relação às fontes de fósforo, as principais são as de intemperismo das rochas e decomposição da matéria orgânica, fertilizantes (PESSOA et al., 2010; BERTECHINI, 2017). A liberação excessiva de nitrogênio e fósforo pode provocar um aumento na população de organismos aquáticos, sendo que o crescimento destes tem como consequência a depleção de oxigênio (LINS, 2010; SOUTO, 2017).

A garantia do consumo humano de água potável, livre de microrganismos patogênicos, de substâncias e elementos químicos prejudiciais à saúde, constitui-se em ação eficaz de prevenção das doenças causadas pela água (BRASIL, 2006; MESQUITA et al., 2014). Os demais parâmetros analisados se mantêm enquadrados nos valores máximo e/ou mínimos permitidos. Ressaltando que, considerando suas evidências, caracterizam água de boa a ótima qualidade. 
A observação do enquadramento dos demais parâmetros ao determinado pela legislação vigente traz dados de conformidade da qualidade da água utilizada para consumo humano, da qual pode ser construído o IQA - Índice de Qualidade de Água para todos os pontos amostrais.

\section{Índice de Qualidade da Água (IQA)}

A apresentação dos índices calculados está organizada na tabela 5, a seguir. É possível observar que em todos os pontos a qualidade da água analisada é considerada 'satisfatória' em ambos os períodos (seco e chuvoso), oscilando entre os níveis 'Bom' e 'Ótimo'.

Tabela 5: Valores de IQA dos pontos amostrais.

\begin{tabular}{|c|c|c|c|c|c|}
\hline Ponto & Identificação & $\begin{array}{l}\text { Valor do } \\
\text { IQAps }^{*}\end{array}$ & $\begin{array}{l}\text { Nível de qualidade - } \\
\text { CETESB }\end{array}$ & $\begin{array}{l}\text { Valor } \\
\text { IQAPC }\end{array}$ & $\begin{array}{l}\text { Nível de qualidade - } \\
\text { CETESB }\end{array}$ \\
\hline P01 & Poço tubular da praça & 70 & Bom & 82 & Ótimo \\
\hline P02 & Poço tubular da caixa & 93 & Ótimo & 82 & Ótimo \\
\hline P03 & $\begin{array}{l}\text { Logo após a estação } \\
\text { elevatória }\end{array}$ & 77 & Bom & 82 & Ótimo \\
\hline P04 & Residência & 77 & Bom & 90 & Ótimo \\
\hline
\end{tabular}

* Índice de Qualidade de Água no Período Seco; ** Índice de Qualidade de Água no Período Chuvoso.

No período seco, em 3 (três) dos 4 (quatro) pontos, ou seja, 75\%, foram enquadradas como nível 'Bom'; enquanto, apenas o 'P02' - local de captação da água para distribuição, foi enquadrado como nível 'Ótimo'. Já no período chuvoso, embora os parâmetros destoantes do permitido pela legislação tenha aumentado - nitrogênio total e fósforo total -, o OD ficou dentro do permitido e $100 \%$ dos pontos foram enquadrados como IQA 'Ótimo'.

Com o enquadramento do parâmetro $O D$ e como este tem um peso maior $(w=0,17)$ que nitrogênio $(w=0,10)$ e fósforo $(w=0,10)$ no cálculo do IQA, o aumento dos valores desses dois últimos no período chuvoso não influenciou no valor calculado do IQA para cada ponto, fato este que manteve os 4 (quatro) pontos com nível de IQA 'Ótimo', sendo influenciados diretamente pelo enquadramento do parâmetro OD, parâmetro com maior peso no cálculo do IQA.

\section{CONCLUSÕES}

Com o comparativo de sazonalidade, os dados observados não sofreram alteração que levasse a desconformidade da maioria dos parâmetros analisados conforme o padrão estabelecido pelas legislações utilizadas. O IQA apresentou nível de qualidade entre bom e ótimo em todos os pontos amostrados e em ambos os períodos. Portanto, o sistema de abastecimento e distribuição apresenta qualidade satisfatória.

\section{REFERÊNCIAS}

AMORIM, D. G.; CAVALCANTE, P. R. S.; SOARES, L. S.; AMORIM, P. E. C.. Enquadramento e avaliação do índice de qualidade da água dos igarapés Rabo de Porco e Precuá, localizados na área da Refinaria Premium I, município de Bacabeira (MA). Eng. Sanit. Ambient., Rio de Janeiro, v.22, n.2, p.251-259, 2017. Dol: https://doi.org/10.1590/s141341522016131212
ANA. Agência Nacional de Águas. Cuidando das águas: soluções para melhorar a qualidade dos recursos hídricos Brasília: ANA, 2011a.

ANA. Agência Nacional de Águas. Indicadores de qualidade índice de qualidade das águas (IQA). Brasília: ANA, 2011b. 
ANA. Agência Nacional de Águas. Atlas Brasil:

Abastecimento Urbano de Água. Brasília: ANA, 2010.

ANA. Agência Nacional de Águas. Panorama da qualidade das águas superficiais do Brasil: 2012. Brasília: ANA, 2012.

ANA. Agência Nacional de Águas. Panorama da Qualidade das águas subterrâneas no Brasil. Brasília: ANA, 2007.

APHA. American Public Health Association. Standard methods for the examination of water and wastewater. 22 ed. Washington: APHA, 2012.

ARAÚJO, L. E.; SOUSA, F. A. S.; MORAES NETO, J. M.; SOUTO, J. S.; REINALDO, L. R. L. R.. Bacias hidrográficas e impactos ambientais. Campina Grande: UEPB, 2009.

ARID, F. M.. Água subterrânea e saúde pública. Geologia, Meio Ambiente e Saúde: Serviço Geológico do Brasil. CPRM, 2019.

BERTECHINI, M. C.. Frações da matéria orgânica do solo em função de fontes e doses de fertilizante mineral e organomineral no cerrado piauiense. Dissertação (Mestrado em Solos e Nutrição de Plantas) - Universidade Federal do Piauí, Bom Jesus, 2017.

BDTD UFMG. Hidroquímica. Universidade Federal de Minas Gerais (UFMG). Biblioteca Digital de Teses e Dissertações (BDTD).

BOMTEMPO, V. L.. Técnicas Isotópicas em Hidrologia e Sedimentologia. In: CONGRESSO GERAL SOBRE ENERGIA NUCLEAR, 7. Anais. Belo Horizonte, 1999.

BRASIL. Lei n. 9.433 de 8 de janeiro de 1997. Institui a Política Nacional de Recursos Hídricos, cria o Sistema Nacional de Gerenciamento de Recursos Hídricos. Brasília: DOU, 1997.

BRASIL. Portaria n. 2914, de 12 de dezembro de 2011. Dispõe sobre os procedimentos de controle e de vigilância da qualidade da água para consumo humano e seu padrão de potabilidade. Brasília: MMA, 2011.

BRASIL. Resolução CONAMA n. 357 de 17 de março de 2005. Dispõe sobre a classificação dos corpos de água e diretrizes ambientais para o seu enquadramento, bem como estabelece as condições e padrões de lançamento de efluentes, e dá outras providências. Brasília: DOU, 2005.

BRASIL. Resolução CONAMA n. 396 de $\mathbf{3}$ de abril de 2008. Dispõe sobre a classificação e diretrizes ambientais para o enquadramento das águas subterrâneas e dá outras providências. Brasília: DOU, 2008.

BRASIL. Vigilância e controle da qualidade da água para consumo humano. Brasília: Ministério da Saúde, 2006.

CAPP, N.; AYACH, L. R.; SANTOS, T. M. B.; GUIMARÃES, S. T. L.. Qualidade da água e fatores de contaminação de poços rasos na área urbana de Anastácio (MS). Geografia Ensino \& Pesquisa, v.16, n.3, 2012.

CELLIGOI, A.. Considerações sobre análises químicas de águas subterrâneas. Geografia, Londrina, v.8, n.1, p.91-97,
1999.

CETESB. Companhia de Tecnologia Ambiental do Estado de São Paulo. Qualidade das águas interiores no estado de São Paulo 2017. São Paulo: CETESB, 2018.

CETESB. Companhia de Tecnologia Ambiental do Estado de São Paulo. Guia de coleta e preservação de amostras de água. São Paulo: CETESB, 1987.

CETESB. Companhia de Tecnologia Ambiental do Estado de São Paulo. Indicadores de Qualidade das Águas. São Paulo: CETESB, 1997.

CUNHA, B. P.; AUGUSTIN, S.. Sustentabilidade ambiental: estudos jurídicos e sociais. Caxias do Sul: EDUCS, 2014.

FUNDAÇÃO CEPRO. Diagnóstico socioeconômico do município de Riacho Frio/PI. Fundação CEPRO, 2011.

IBGE. Instituto Brasileiro de Geografia e Estatística. Área territorial oficial-2002. Resolução da Presidência do IBGE de n. 5 (R.PR-5/02). IBGE, 2002.

INFOSANBAS. Cooperativa EITA. INFOSANBAS, 2017.

JACOBI, P.. Educação ambiental, cidadania e sustentabilidade. Cad. Pesqui., São Paulo, n.118, 2003. DOI: https://doi.org/10.1590/S0100-15742003000100008

LINS, G. A.. Impactos ambientais em estações de tratamento de esgotos (ETEs). Dissertação (Mestrado em Engenharia Ambiental) - Universidade Federal do Rio de Janeiro, Rio de Janeiro, 2010.

LUSTOSA, R. V.; LIMA, T.P.; SOUZA, I. R. M.; ROCHA, I. L.. Panorama do abastecimento de água no município de Riacho Frio, Piauí. In: CONGRESSO NORTE NORDESTE DE PESQUISA E INOVAÇÃO, 11. Anais. Maceió: CONNEPI, 2016.

MESQUITA, K. F. C.; SANTOS, M. L. S.; PEREIRA, J. A. R.; FIGUEIREDO, B. L.. Avaliação da qualidade microbiológica da água consumida pela população da região amazônica um estudo de casos na ilha de Mosqueiro PA. Scientia Amazônia, v.3, n.3, p.27-31, 2014.

NANES, P. L. M. F.. Qualidade das águas subterrâneas de poços tipo cacimba: um estudo de caso da comunidade nascença: município de São Sebastião/AL. In: CONGRESSO BRASILEIRO DE GESTÃO AMBIENTAL. Anais. Goiânia: IBEAS, 2012.

NASCENTES, C. C.; COSTA, L. M.. Química Ambiental. Belo Horizonte: UFMG, 2011.

OLIVEIRA, B. S. S.; CUNHA, A. C.. Correlação entre qualidade da água e variabilidade da precipitação no sul do Estado do Amapá. Rev. Ambient. Água, Taubaté, v.9, n.2, 2014. DOI: https://doi.org/10.4136/ambi-agua.1287

PESSOA, C. A.; JORDÃO, E. P.. Tratamento de esgotos domésticos. 4 ed. Rio de Janeiro: ABES, 2010.

ROCHA, E. S.; ROSICO, F. S.; SILVA, F. L.; LUZ, T. C. S.; FORTUNA, J. L.. Análise microbiológica da água de cozinhas e/ou cantinas das Instituições de Ensino do município de Teixeira de Freitas (BA). Revista Baiana Saúde Pública, 
Salvador, v.34, n.3, 2010.

ROCHA, I. L.. Qualidade ambiental das nascentes do rio Paraim, extremo Sul do Piauí. Dissertação (Mestrado em Conservação de Recursos Naturais do Cerrado) - Instituto Federal Goiano, Urutaí, 2019.

SILVA, R. C. A.; ARAÚJO, T. M.. Qualidade da água do manancial subterrâneo em áreas urbanas de Feira de Santana (BA). Ciência \& Saúde Coletiva, v.8, n.4, p.10191028,2003

SILVA, J. M.; SANTOS, G. O.; ALMEIDA JÚNIOR, M. C. D.; GUIMARÃES, A. G.; DOMINGOS, G. S.. Qualidade da água de captação para abastecimento público no município de Maurilândia, Goiás. Caminhos de Geografia, Uberlândia, v.18, n.64, p.199-213, 2017.

SOUTO, C. N. C.. Estudo de reatores em bateladas sequenciais para a remoção simultânea de nitrogênio e fósforo no tratamento de esgoto sanitário. Dissertação (Mestrado em Engenharia Civil) - Universidade Federal de Pernambuco, Recife, 2017.
STROHSCHOEN, E.; ECKARDT, R. R.; DIEDRICH, V. L.; RIGELO, E. F.. Diagnóstico da água subterrânea no município de Lajeado/RS. In: CONGRESSO BRASILEIRO DE ÁGUAS SUBTERRÂNEAS. Anais. 2006. p.1-19.

VON SPERLING, M.. Introdução à qualidade da água e ao tratamento de esgotos. 3 ed. Belo Horizonte: UFMG, 2005.

VON SPERLING, M.. Introdução à qualidade das águas e ao tratamento de esgotos. 4 ed. Belo Horizonte: UFMG, 2014.

VOTTRI, M.. Geoprocessamento integrado à modelagem hidrológica para o diagnóstico ambiental e a qualificação de cenários de uso e perda de solo na bacia hidrográfica do Rio Vitorino/PR. Dissertação (Mestrado em Desenvolvimento Regional) - Universidade Tecnológica Federal do Paraná, Pato Branco, 2018.

WARD, N. D.; KEIL, R. G.; MEDEIROS, P.; BRITO, D. C.; CUNHA, A. C.; DITTMAR, T.. Degradation of terrestrially derived macromolecules in the Amazon River. Nature Geoscience, v.6, n.6, p.1-4, 2013. DOI: http://dx.doi.org/10.1038/ngeo1817

A CBPC - Companhia Brasileira de Produção Científica (CNPJ: 11.221.422/0001-03) detém os direitos materiais desta publicação. Os direitos referem-se à publicação do trabalho em qualquer parte do mundo, incluindo os direitos às renovações, expansões e disseminações da contribuição, bem como outros direitos subsidiários. Todos os trabalhos publicados eletronicamente poderão posteriormente ser publicados em coletâneas impressas sob coordenação da Sustenere Publishing, da Companhia Brasileira de Produção Científica e seus parceiros autorizados. Os (as) autores (as) preservam os direitos autorais, mas não têm permissão para a publicação da contribuição em outro meio, impresso ou digital, em português ou em tradução. 